\title{
CUESTIONES CENTRALES DE LA ACTUAL FILOSOFÍA DE LA IMAGEN
}

\section{CENTRAL ISSUES OF THE CURRENT PHILOSOPHY OF THE IMAGE}

\author{
Roberto Rubio'
}

RESUMO: En el contexto de la Bildwissenschaft han surgido, desde hace unas décadas, desarrollos filosóficos orientados al fenómeno de la imagen. Se trata de la actual "Filosofía de la imagen". El presente trabajo se concentra en dos cuestiones centrales para la Filosofía de la imagen. En primer lugar, se abordará la pregunta por el estatuto exhibitorio de las imágenes. En segundo lugar, se considerará la cuestión acerca de la condición medial de estas. Por último, se ofrecerá un análisis crítico de los debates correspondientes a tales cuestiones.

Palavras-chave: Bildwissenschaft; Filosofía de la imagen; Condición medial de las imágenes.

ABSTRACT: Philosophical developments regarding the phenomenon of image have arisen since a few decades in the context of Bildwissenschaft. It is the current "Philosophy of Image". The present work addresses two central topics for the Philosophy of Image. Firstly, we will consider the question concerning the exhibitionary status of images. Secondly, the issue of the mediational conditions of images will be discussed. Finally, we will offer a critical analysis of the debates that correspond to these topics.

Keywords: Bildwissenschaft; Philosophy of image; Mediality of images.

Desde hace algunas décadas, se desarrolla en el ámbito germano-parlante un proyecto interdisciplinario dirigido al estudio de las imágenes. Se trata de la Bildwissenschaft o Ciencia de la imagen. ${ }^{2}$ Ella pretende integrar en un marco común el aporte de diversas disciplinas, tales como la historia del arte, la teoría del arte, la filosofía y la psicología, entre otras.

La contribución de la filosofía al programa de la Bildwissenschaft ha dado lugar a la así denominada "filosofía de la imagen". ${ }^{3}$ Ella es especialmente sensible a los intentos de renovación paradigmática que afectan de modo más o menos directo a la cuestión de la imagen, tales como el "giro performativo", el "giro icónico" o el "giro medial".

\footnotetext{
Licenciado en Filosofía por la Universidad Nacional de Salta (Argentina) y Doctor en Filosofía por la Universidad de Friburgo (Alemania). Profesor de Filosofía en la Universidad Alberto Hurtado (Chile). Allí dirige el Programa de Magíster en Filosofía.

2 Ver Sachs-Hombach, 2005; Schulz, 2005; García Varas, 2012; Hornuff , 2012; McPhail, 2013, pp. 90-105

3 Ver Hügli et al. 2010 y Wiesing, 2005.
} 
A continuación, expondré dos cuestiones centrales en la filosofía de la imagen. Presentaré, en primer lugar, la pregunta por el estatuto exhibitorio de las imágenes, y en segundo lugar, la pregunta acerca de la condición medial de las imágenes. Luego de la exposición, ofreceré un análisis crítico de los debates correspondientes a tales cuestiones

\section{El estatuto exhibitorio de las imágenes}

La filosofía de la imagen se propuso en sus inicios la tarea de una definición sobre la imagen. La pregunta "¿Qué es una imagen?" dio título a una influyente antología de artículos publicada por Gottfried Boehm en 1995. Ahora bien, durante el desarrollo de esa tarea de aclaración conceptual, la discusión se orientó preferentemente hacia las imágenes exhibitorias, esto es, hacia las superficies visibles en las que aparece algo como estando allí presente. El fenómeno de la exhibición se convirtió en un eje central para desarrollar la indagación filosófica acerca de la imagen. En otras palabras, la cuestión general ¿qué es una imagen? fue reencauzada en la siguiente pregunta específica: ¿cómo una superficie visible puede remitir hacia algo que no está allí en persona y hacerlo presente en cierto modo?

En torno a esta pregunta se articuló un debate que aun se encuentra vigente. De acuerdo a la influyente recreación del debate ofrecida por Lambert Wiesing, ${ }^{4}$ se oponen principalmente dos enfoques. Uno sostiene que la imagen exhibitoria remite significativamente hacia algo y que, por tanto, se trata de un tipo especial de signo. El otro, en cambio, se centra en la experiencia de imagen, a la que considera como la captación de algo presente en imagen. Respecto de ella, se afirma que es una experiencia derivada de la percepción sensible. Ambos planteos son caracterizados por los especialistas como las concepciones «semiótica» y «perceptualista» de la imagen, respectivamente. ${ }^{5}$ Entre los representantes del enfoque semiótico suele ser considerada la semiótica anglo-norteamericana y algunos autores de filosofía del lenguaje, en particular Nelson Goodman. ${ }^{6}$

Por su parte, como representante del enfoque perceptualista suele ser considerada la fenomenología.7

De acuerdo a Wiesing (2005, 32-33), el centro del debate es la estructura de la exhibición (Darstellung) propia de las imágenes. Por "exhibición" se entiende aquí, en términos generales, el proceso por el cual una aparición sensible hace presente algo que no se encuentra allí en persona. Según Wiesing (33 sg.), las posiciones enfrentadas en el debate coinciden en señalar tres momentos estructurales de la exhibición, a los que Wiesing denomina lo exhibitorio, la exhibición en cuanto tal y lo exhibido. Esta t

\footnotetext{
4 Ver Wiesing 2005, pp. 30-34. La reconstrucción del debate ofrecida por Wiesing es tomada directamente por Schulz (2009, pp. 92-94) y García Varas (2012, pp. 32-33), entre otros.

$5 \quad$ Seel 2003, 282; Sachs-Hombach 2005, 113-114; Wiesing 2005, 17-36; Schweppenhäuser 2007, pp. 258259.

$6 \quad$ Wiesing 2005, pp. 72-74; Sachs-Hombach 2005, pp. 114-115; Schweppenhäuser 2007, 250-251, 282.

$7 \quad$ Schulz 2005, pp. 92-93; Wiesing 2005, pp. 30-32, p. 68.

8 Para un análisis detallado de la presentación de Wiesing, ver Rubio (2017).
} 
El contraste mencionado involucra dos modos de concebir la experiencia de imágenes: o bien como lectura de imágenes, dirigida a alcanzar un sentido lingüístico o quasi-linguístico; o bien, como la captación de objetos imaginarios sobre superficies visibles. La contraposición planteada por Wiesing $(2005,34)$ entre leer imágenes (en cuanto signos) y ver imágenes (en cuanto objetos imaginarios) conduce, en última instancia, hacia una oposición de fondo entre la experiencia de remisión intencional, por un lado, y la experiencia de presentación sensible, por otro:

Mostrar algo en imagen no quiere decir que con la imagen haya que referir a algo, sino que algo es presentado artificialmente: algo se vuelve visible y nada más que eso. (...) Contemplar y estudiar un asunto también un objeto-imagen no hace de tal asunto un signo. Los signos surgen por el uso y no por la intuición (WIESING, 2005, 36).

Siguiendo el encuadre propuesto por Wiesing, además de las posiciones representativas de ambos extremos (las aproximaciones semióticas por un lado, la fenomenología clásica por otro), se observan enfoques intermedios. Entre ellos destacan el planteo de Sachs-Hombach acerca de las imágenes como "signos perceptoides"9 y la propuesta de Wiesing, según la cual la experiencia de imagen combina la captación de un objeto exclusivamente visual con el uso de este como base material para la conexión significativa con un referente. ${ }^{10}$

\section{La condición medial de las imágenes}

Entre la Bildwissenschaft y las ciencias de los medios (Medienwissenschaften) no hubo inicialmente intercambios, sino más bien distanciamiento. ${ }^{11}$ Sin embargo, esto ha cambiado en los últimos años. La condición medial o "medialidad" de las imágenes se ha convertido en un asunto central para la filosofía de la imagen. En la última década se ha consolidado un debate filosófico con alcance interdisciplinario, en el que participan filósofos de la imagen y filósofos de los medios. Entre las principales figuras de este debate hay que mencionar a Sybille Krämer, Dieter Mersch, Emmanuel Alloa y Lambert Wiesing. ${ }^{12}$

En la filosofía de la imagen, el interés por la medialidad se ha canalizado en dos tareas fundamentales: en primer lugar, aclarar el estatuto y funcionamiento de las imágenes considerando su específico carácter medial. En segundo lugar, repensar, en diálogo crítico con la filosofía de los medios, las nociones generales de "medio", "mediación" y "medialidad". ${ }^{13}$

La primera tarea ha recibido impulsos decisivos del programa de la "antropología de la imagen" de Hans Belting. Este afirma:

\footnotetext{
$9 \quad$ Sachs Hombach 2002, p. 21 sg.

$10 \quad$ Wiesing 2005, pp. 50-51.

11 Ver Günzel 2014, p. 123 sg.

12 Cf. Krämer 2012, Alloa 2011, Wiesing 2012, Mersch 2105.

13 Cf. Alloa 2011, p. 266.
} 
En el discurso actual, las imágenes o bien se consideran en un sentido tan abstracto que parecen estar desprovistas de medio y carentes de cuerpo, o bien se confunden simplemente con sus respectivas técnicas. En un caso se reducen al mero concepto de imagen, en el otro a la mera técnica de la imagen. (BELTING, 2010, 26)

A fin de evitar ambos reduccionismos respecto a las imágenes, Belting propone un estudio orientado hacia "la praxis de la imagen, lo cual requiere un tratamiento distinto al de las técnicas de la imagen y su historia" $(2009,10)$.

La tendencia de Belting por incorporar la dimensión medial en los estudios sobre imagen con una mirada enfocada en la experiencia de imagen y no en las técnicas de imagen ha sido continuada y reelaborada por filósofos de la imagen de inspiración fenomenológica (ALLOA, MERSCH, SCHÜRMANN, BOEHM, entre otros). Para ellos, el estudio del carácter medial de las imágenes no consiste en analizar los medios y conocimientos técnicos que intervienen en la producción y circulación de imágenes, sino en describir las mediaciones operantes en la experiencia de imagen.

El fenómeno central de la medialidad de imagen, descrito por los autores de inspiración fenomenológica, es el siguiente: en la experiencia de imagen, en cuanto experiencia de algo que aparece visiblemente como estando allí presente, vivenciamos la tensión entre la manifestación de los elementos materiales -lo cual incluye los rastros de procedimientos técnicos empleados-', y la oferta visible imaginaria (la configuración que aparece). Dicha tensión se experimenta como el proceso del "surgir mediante ..." o "aparecer a través de ...". En este sentido, Alloa enfatiza el "transparecer" o "aparecer a través de" (Durch-scheinen) como la medialidad característica de la experiencia de imagen. ${ }^{14}$ En una dirección semejante, Waldenfels caracteriza a la imagen como "medio" en dos sentidos complementarios: por una parte, en la experiencia del ver algo en imagen, la imagen hace posible el volverse visible de lo que allí vemos; por otra parte, la imagen es el medio para el acontecimiento de un efectuar que concierne a quienes hacen la experiencia de imagen. Ese efectuar es vivido como un afectar demandante, es decir, como una apelación que reclama respuesta (WALDENFELS 2010, 117 f.).

Como se puede advertir, aun cuando la filosofía de la imagen ingresa en el horizonte temático de las ciencias de los medios, su enfoque no apunta a caracterizar las imágenes clasificándolas a partir de una noción de "medio" proveniente de las Medienwissenschaften. En otras palabras, no intenta responder cuestiones como “qué tipo de medio son las imágenes?"; "¿son medios estrictamente visuales o también plásticos?", etc. No se trata de recurrir a una noción de "medio" ya disponible, para luego aplicarla al caso de las imágenes, sino de describir los procesos de mediación específcos en la experiencia de imagen. La medialidad considerada en el enfoque de filosofía de la imagen es una medialidad intrínseca a la imagen, o dicho con otras palabras: una medialidad constitutiva de la experiencia de imagen.

Ahora bien, algunos filósofos de la imagen de orientación fenomenológica (ALLOA, WALDENFELS, MERSCH, SCHÜRMANN, entre otros) avanzaron, sobre la base de sus estudios de la medialidad intrínseca de la imagen, hacia una reflexión sobre las nociones generales de "medio", "mediación” y "medialidad”.

$14 \quad$ Alloa, 2011, 320 sg. 
En términos generales, se puede entender la medialidad como el conjunto de características constitutivas de un medio, es decir, lo que hace que un medio sea un medio. Asimismo, en términos generales se puede entender "mediación" como el proceso en el cual un medio es propiamente un medio. Empleadas así estas nociones, sin asignarle mayores determinaciones y sin vincularlas aun a ningún tipo específico de evento o experiencia, son nociones formales, cuyo valor es programático. Dicho valor consiste en orientar una investigación básica que vaya más allá de la descripción de casos particulares y se proponga descubrir estructuras generales. Al respecto, afirma Mersch:

Las ciencias de los medios poseen la peculiaridad de que trabajan con conceptos que ellas presuponen. Esto vale ante todo para el concepto de "medio". A menudo se tematizan medios particulares como el medio literario, el film o los juegos de computador, sin aclarar lo específico de su medialidad. Lo mismo ocurre con aquellos planteos de teoría de los medios que utilizan el término "medios" en plural para referir a formas de la transmisión técnica o de la operatividad. ${ }^{15}$

Para caracterizar con la debida precisión el ámbito de la discusión general sobre medios en la cual intervienen los planteos provenientes de la filosofía de la imagen, debemos distinguir entre dos enfoques generales sobre medios: el de la teoría general de los medios y el de la filosofía de los medios.

Siguiendo a Mersch $(2013,90)$, podemos decir que con la así denominada "escuela canadiense" (MC LUHAN, INNIS, ONG, entre otros), aparece por primera vez una teoría general de los medios. Dicha "escuela" surgió en los años 60 en el Centre por Culture and Technology de la universidad de Toronto. Se trataba de un grupo de especialistas en diversas disciplinas (antropología social, crítica literaria, filología, historia) dedicados a estudiar la influencia de los medios de comunicación, en particular la escritura, en la configuración social y cultural. Sobre la base de sus estudios se consolidó la tarea programática de realizar una "teoría de los medios" en el sentido de un diagnóstico histórico-cultural orientado a esclarecer los cambios de época a partir de transformaciones técnicas en la comunicación.

Bajo influencia de la escuela canadiense, entre otros planteos, tuvo lugar en Alemania la conformación de las "Ciencias de los medios". El corpus teórico básico de estas comprende un amplio espectro que va desde los estudios de la escuela canadiense hasta el "medial turn", pasando por la crítica de los medios postmoderna. El enfoque de "teoría general de los medios" desde el cual se agrupan estos diversos planteamientos, se articula sobre la tesis según la cual los cambios técnicos en los medios y modos de comunicación son una clave fundamental para explicitar la configuración social y cultural y los cambios de época.

Junto con la consolidación de las ciencias de los medios tiene lugar el desarrollo de la Filosofía de los medios. Señalemos dos rasgos centrales de esta: por un parte, realiza un análisis crítico de los conceptos y propuestas teóricas de las Medienwissenschaften. Por otra parte, reflexiona sobre los medios en un nivel de estudio que podríamos llamar "ontológico". En dicho nivel, el rol fundante asignado a los medios desde el enfoque

$15 \quad$ Mersch 2015, p. 13. 
de una teoría general de los medios - sea como productores de subjetividades, constitutivos del sistema social, o bien como configuradores de la cultura en la era de la información - es considerado a la luz de la pregunta por la estructura fundamental de lo que es. En este sentido, se habla de "medialidad" y de "mediación" como la estructura general y el proceso general de formación de lo que hay, respectivamente. ${ }^{16}$ En este nivel de estudio se desarrollan también las concepciones que involucran una "crítica de la metafísica", como por ejemplo las teorías postmodernas y deconstructivistas sobre medialidad.

Hechas estas aclaraciones, podemos decir que la filosofía de la imagen ofrece planteos correspondientes al debate ontológico sobre medialidad y mediación - debate que pertenece al campo de la filosofía de los medios-. ${ }^{17}$ Uno de los planteos de la filosofía de la imagen más provocativos es el siguiente: con las imágenes acontece un proceso de mediación sui generis, situado en el ámbito de la experiencia vivida, el cual no deriva de la percepción habitual de cosas, ni de sistemas de signos, ni de procesos técnicos de computación y digitalización, pero que puede influir en ellos.

\section{Análisis crítico de los principales debates en filosofía de la imagen}

A continuación, analizaremos los debates en filosofía de la imagen vinculados a las cuestiones presentadas en los puntos 1 y 2 . En primer lugar consideraremos el debate respecto al carácter exhibitorio de las imágenes. Luego analizaremos el debate sobre la condición medial de las imágenes.

Como hemos visto, la reconstrucción usual del debate sobre el estatuto exhibitorio de las imágenes destaca dos enfoques antagónicos, a saber: el perceptualista y el semiótico. A la luz de esa oposición han surgido también propuestas "de vía media".

El encuadre vigente del debate merece una revisión crítica. En primer lugar, cabe considerar la manera cómo se lleva a cabo dicho encuadre. Este se basa sobre una estilización de los enfoques perceptualista y semiótico, según la cual cada uno de ellos enfatizaría funciones y aspectos fundamentales y opuestos de la exhibición icónica: por una parte, la función de hacer presente algo sensiblemente, por la cual la experiencia de imagen se conectaría con la percepción, y por otra, la función de referir mediante significados, por la cual las imágenes constituirían un tipo particular de signos, derivado de los signos lingüísticos. En relación con la primera función, se enfatiza el carácter de configuración sensible de las imágenes. En relación con la segunda función, en cambio, se enfatiza el carácter convencional, cultural e históricamente determinado de las imágenes.

Ahora bien, ese modo de articular el debate no considera a cabalidad los enfoques participantes y deja fuera de consideración aspectos centrales de los mismos. Con

16 Cf. Krämer 2004, pp. 21-23.

17 Ver Mersch 2015. Es especialmente relevante la distinción que Mersch traza allí entre el enfoque de ciencias de los medios y el de filosofía de los medios. 
respecto a la fenomenología, por ejemplo, no tiene en cuenta los planteos de Husserl sobre las relaciones de identidad y diferencia entre objeto-imagen y tema-imagen. Y con respecto al enfoque semiótico, deja sin consideración teorías semióticas que destacan la relevancia de la configuración sensible de la imagen para la comunicación.

En segundo lugar, las propuestas que intentan construir una vía media quedan expuestas al riesgo del eclecticismo, en la medida en que reúnen desarrollos puntuales de cada enfoque sin analizar la compatibilidad de los respectivos marcos teóricos puestos en juego.

Un tercer punto a tener en cuenta es el supuesto de fondo que organiza la estrategia de polarización con la que se encuadra el debate. Dicho supuesto consiste en la oposición entre presentación perceptual, por una parte, y representación o referencia mediante significados, por otra. Junto a esta oposición se han construido otras, como la oposición entre mostrar y decir. ${ }^{18}$ Ahora bien, ese supuesto fundamental implica convicciones polémicas, como el carácter inmediato y la presencia originaria de la percepción sensible. ${ }^{19}$

Consideremos a continuación la segunda cuestión central en la agenda de la filosofía de la imagen, es decir, la medialidad de las imágenes. Como hemos visto, esta cuestión se ha desarrollado en dos niveles. En primer lugar, la filosofía de la imagen, particularmente autores de inspiración fenomenológica, ha abordado la cuestión de la medialidad con el fin de esclarecer la estructura y función de las imágenes. En segundo lugar, esos mismos autores han considerado la medialidad intrínseca de las imágenes como base para repensar la mediación en cuanto proceso configurador originario. En este sentido, han avanzado hacia el campo de la filosofía de los medios y han impulsado una renovación del debate ontológico sobre medialidad y mediación.

A continuación, nos concentraremos en este último punto. La renovación del debate en "ontología de los medios" (Medienontologie) enfrenta particularmente a una línea de la filosofía de la imagen -aquella de inspiración fenomenológica-, con la línea de la filosofía de los medios que proviene del "giro medial" alemán, centrado en la figura de Friedrich Kittler.

Kittler promueve un "giro hacia los medios" en el contexto de las ciencias de la cultura, lo cual tiene además alcances filosóficos. Se pueden destacar allí los siguientes énfasis: en primer lugar, la focalización en la comunicación como clave para entender los procesos de configuración cultural; en segundo lugar, la focalización en los medios masivos de comunicación, y particularmente en los new media, para entender los procesos de comunicación.

A partir de tales énfasis cabe entender la propuesta filosófica de Kittler, la cual sitúa en los procedimientos técnicos de la computación (el registro, procesamiento y transferencia de información) la mediación ontológicamente originaria. Algunos aspectos filosóficos para destacar son los siguientes: en primer lugar, el enfoque materialista. Kittler propone un "materialismo de la información"20, para el cual bien vale

\footnotetext{
18 Ver Mersch 2014.

19 Una versión más detallada de este análisis del debate se encuentra en Rubio 2017.

$20 \quad$ Kittler 1993, p. 182.
} 
el título de un volumen editado por él en 1980: "La expulsión del espíritu fuera de las ciencias del espíritu". ${ }^{21}$ El segundo aspecto a destacar es el enfoque acerca de los medios centrado en procesos técnicos. Este enfoque acentúa la autonomía de los procesos técnicos respecto a procesos de mediación de sentido y dirección referencial. Más aún, sugiere la dependencia de sentido y referencia respecto al procesamiento de información. Para articular esta propuesta, Kittler recurre a los principios de McLuhan y a la noción derridiana de "archi-escritura", la cual resulta interpretada ahora como las notaciones simbólicas que permiten los procesos de cálculo y computación.

Es el propio Kittler quien extrae las consecuencias de su planteo para una investigación ontológica. En su conferencia dictada en Estambul el 22 de agosto de 2004, titulada "Fenomenología versus Ciencias de los medios" Kittler propone, frente a la fenomenología de Husserl y los desarrollos de Heidegger, una "ontología de la materia calculante". Frente a la orientación fenomenológica dirigida a la percepción habitual, Kittler se orienta hacia la "vida de segundo grado" generada por computadoras: "scientific visualisation. Artificial Life".22

Contra Kittler, los filósofos de la imagen de inspiración fenomenológica han enfatizado los siguientes aspectos programáticos: la corporalidad vivida, la performatividad de la praxis vital, los procesos subjetivos e intersubjetivos de constitución de sentido y experiencia de presencia.23

A la luz de tal debate, considero relevante puntualizar las tensiones de fondo sobre las cuales surge. En tal tarea de discernimiento consiste mi análisis crítico. Mencionaré esas tensiones de modo escalonado, desde las diferencias más profundas hasta la oposición más notoria, esto es, aquella oposición según la cual la computadora, en un caso, y la corporalidad vivida, en otro, son paradigmas de medialidad.

La tensión más profunda es la siguiente: Kittler, bajo inspiración derridiana y extendiendo su influencia a Gumbrecht, considera que hay exterioridad originaria respecto al sentido (a esto lo denomina "materialismo"). Los enfoques fenomenológicos consideran, por su parte, que sentido y presencia son dimensiones originarias y concomitantes, incluso aceptando una exterioridad respecto al sentido.

Sobre ello se articula una segunda oposición: Kittler sitúa la mediación originaria en procesos anónimos de diferenciación entre marcas de un sistema de cálculo. Los fenomenólogos, en cambio, la sitúan en procesos de experiencia vivida, es decir, en la praxis subjetiva e intersubjetiva.

En tercer lugar, Kittler se orienta hacia procesos de transferencia, mientras que los fenomenólogos se orientan hacia procesos de exhibición (Darstellung). ${ }^{24}$

Por último, y a partir de lo anterior, alcanzamos la oposición más notoria: para Kittler el paradigma de mediación es la Máquina de Turing, o Máquina discreta universal, capaz de provocar experiencias virtuales. ${ }^{25}$ Para los fenomenólogos, el paradigma

\footnotetext{
$21 \quad$ Kittler 1980.

22 Kittler, 2004.

23 Ver especialmente Mersch 2015, p. 2, pp. 6-7, pp. 11-13, p. 25 sg.

24 Tomo esta idea de Dieter Mersch $(2015,6)$.

$25 \quad$ Kittler 1993, p. 228.
} 
de mediación es la corporalidad vivida (Leib), cuya dimensión primaria es la percepción habitual. ${ }^{26}$

\section{Síntesis a modo de cierre}

La Filosofía de la imagen, surgida a fines de los ańos 90, se encuentra actualmente en un proceso de ampliación y revisión crítica. Por una parte, se elevan planteos críticos que procuran una revisión de aspectos fundamentales, como por ejemplo la manera en que se han articulado algunos debates internos. Por otra parte, algunas tendencias al interior de la filosofía de la imagen avanzan hacia campos de discusión inicialmente distantes y promueven una renovación de los mismos. Un ejemplo especialmente relevante de esto es el reciente surgimiento de un ámbito de debate entre filósofos de la imagen y teóricos de los medios, concentrado especialmente en la discusión entre la fenomenología de la imagen y los alcances ontológicos del giro medial impulsado por Friedrich Kittler.

$26 \quad$ Ver especialmente Waldenfels 2015, pp. 194-197. 


\section{REFERÊNCIAS BIBLIOGRÁFICAS}

ALLOA,E.(2011).DasdurchscheinendeBild.Kontureneiner medialenPhänomenologie. Zürich: Diaphanes.

BELTING, H. (2010). Antropología de la imagen. Buenos Aires: Katz Editores.

GARCÍA VARAS, A. (Ed.) (2012). Filosofía de la imagen. Salamanca: Universidad de Salamanca.

HORNUFF, D. (2012). Bildwissenschaft im Widerstreit. Munich: Fink.

HÜGLI, A. \& Chiesa, C. (Eds.) (2010). Philosophie des Bildes - Philosophie de l'image. Basilea: Schwabe.

HUSSERL, E. (1967). Investigaciones Lógicas. (M. García Morente \& J. Gaos, Trad.). Madrid: Selecta de Revista de Occidente.

. (1980). Phantasie, Bildbewusstsein, Erinnerung. La Haya: Nijhoff.

(2013). Ideas relativas a una fenomenología pura y una filosofía fenomenológica. (J. Gaos, Trad.; A. Zirión, revisión). México: FCE.

KANT, I. (1986). Antropologie in pragmatischer Hinsicht. Gottinga: Meiner.

. (2006). Kritik der Urteilskraft. Gottinga: Meiner.

KITTLER, Fr. (Ed.) (1980) Austreibung des Geistes aus den Geisteswissenschaften. Paderborn: Schöningh.

. (1993). Draculas Vermächtnis. Technische Schriften. Leipzig: Reclam.

(2004). Phänomenologie versus Medienwissenschaft (Conferencia dictada en Estambul el 22.8.2004. Disponible online en: http://www.hydra.umn.edu/kittler/istambul.html

KRÄMER, S. (2004). „Die Heteronomie der Medien. Versuch einer Metaphysik der Medialität im Ausgang einer Reflexion des Boten“. Journal Phänomenologie 22, pp. 18-38.

(2012), Medien, Boten, Spuren“. En Münker, St. y Roesler, A. (Eds.) Was ist ein Medium? Fráncfort: Suhrkamp, pp. 65-90.

MCPHAIL E. (2013). Desplazamientos de la imagen. México: Siglo XXI.

MERSCH, D. (2013). Medientheorien. Zur Einführung. Hamburgo: Junius.

. (2014). Zeigen - Etwas-Zeigen - Sichzeigen“. En Günzel, St y Mersch, D. (Eds.) Bild. Ein interdisziplinäres Handbuch. Stuttgart: Metzler, pp. 312-318.

(2015). Wozu Medienphilosophie? Eine programmatische Einleitung“. Internationales Jahrbuch für Medienphilosophie. 1, 1, pp. 13-48.

RUBIO, R. (2017). La reciente filosofía de la imagen. Análisis crítico del debate actual y consideración de posibles aportes. Ideas y Valores 66 (163), 273-298.

SACHS-HOMBACH, K. (Ed.) (2005). Bildwissenschaft. Disziplinen, Themen Methoden. Fráncfort: Suhrkamp. 
. (2002). “Bildbegriff und Bildwissenschaft." Kunst-Gestalt-design 8. Hrsg. Dietfried Gerhardus und Sigurd Rompza. Saarbrücken: St. Johann, pp. 6-25.

SEEL, M. (2003). Ästhetik des Erscheinens. Fráncfort, Suhrkamp.

SCHULZ, M. (2005). Ordnungen der Bilder. Eine Einführung in die Bildwissenschaft. Munich: Fink.

SCHWEPPENHÄUSER, G. (2007). Ästhetik. Philosophische Grundlagen und Schlüsselbegriffe. Fráncfort: Campus Verlag.

VOLONTÉ, P. (1997) Husserls Phänomenologie der Imagination. Munich: Alber.

WALDENFELS, B. (2015) Phänomenologie der Aufmerksamkeit. Fráncfort: Suhrkamp. WIESING, L. (2005). Artifizielle Präsenz.Studien zur Philosophie des Bildes. Fráncfort: Suhrkamp.

. (2012), Was sind Medien?" En Münker, St. y Roesler, A. (Eds.) Was ist ein Medium? Fráncfort: Suhrkamp, pp. 235-248.

. (2013). Sehen Lassen. Die Praxis des Zeigens. Fráncfort: Suhrkamp.

WIRTH, S. (2014). "Medientheorie: Bilder als Techniken“. En Günzel, St y Mersch, D. (Eds.) Bild. Ein interdisziplinäres Handbuch. Stuttgart: Metzler. 